\title{
Nutritional characteristics and physiological studies on the growth and development of Phlebiopsis gigantea
}

\author{
I. B. Prasher ${ }^{1}$, Sushma Negi ${ }^{2 *}$, Rajeev Kumar ${ }^{2}$ \\ 'Department of Botany, Mycology and Plant Pathology Laboratory, Panjab University, Chandigarh, India, 'Department of \\ Environmental Studies, Panjab University, Chandigarh, India
}

\author{
Received: 22-02-2017 \\ Accepted: 31-05-2017 \\ Published: 03-06-2017 \\ *Address for \\ correspondence: \\ Sushma Negi, Department \\ of Environmental Studies, \\ Panjab University, \\ Chandigarh, India. \\ Phone:+91-7837452698. \\ E-mail: sushi.negi14@gmail. \\ com
}

\begin{abstract}
Physiological studies pertaining to the effect of physical factors, carbon and nitrogen requirement of Phlebiopsis gigantea were conducted to know its behavior in vitro. These studies have revealed interesting results regarding its growth and reproduction behavior. The best medium for the optimum growth is glucose-peptone medium. The optimum temperature $\left(28^{\circ} \mathrm{C}\right)$ and $\mathrm{pH}(5.0)$ is required for the optimum mycelial production of $P$. gigantea after 12 days of incubation. The fungus shows best growth in $\mathrm{D}(+)$ glucose and sodium nitrate whereas least growth is observed in sucrose and ammonium nitrate medium among various carbon and nitrogen sources, respectively, DL-threonine is found to be best among various organic nitrogen compounds for the growth of fungal mycelium.
\end{abstract}

KEY WORDS: Nutritional requirements, Phlebiopsis gigantea, wood rotting fungi

\section{INTRODUCTION}

Wood rotting fungi act as a decomposer and recycler of nutrients in the natural ecosystem. These fungi have been alienated into brown, white, and soft-rot fungi, which are able to grow abundantly on wood which is a rich source of carbon, but deficient in nitrogen source. The growth of these fungi needs perceptive control of their nitrogen economy which is essential for proteinase activity in wood, and for the intracellular restructuring of nitrogen from mycelial protein (Wadekar et al., 1995) Phlebiopsis gigantea (syn. P. gigantea, P. gigantea) belongs to the phylum Basidiomycota is a white rot fungi. It is commonly found on dead wood growing on Indian Himalayas and Bhutan (Prasher, 2015). It is a saprotroph which derives its carbon from already dead cells. It has not been reported as a pathogen on mature woody trees, however, evidence of colonization of non-suberized spruce seedling roots has been demonstrated which suggest that it may occur as a potential facultative pathogen (Pratt et al., 1999; Pratt et al., 2000; Sui et al., 2009). It is capable of forming structures in spruce wood that are similar to the mycorrhizal mantle on the tree roots (Vasiliauskas et al., 2007). It has also been investigated for its immediate colonization of stump wood competitive ability against
Heterobasidion annosum and its capability to turn out a large amount of asexual spores in culture (Hacskaylo et al., 1954; Asiegbu et al., 1996; Woodward et al., 1998). In spite of such a large number of morphological attributes of this fungus; which can be exploited commercially; no studies have been conducted for optimizing the growth of P. gigantea with respect to different physical factors such as temperature, $\mathrm{pH}$, days of incubation, and effect of different carbon and nitrogen requirement.

\section{MATERIALS AND METHODS}

P. gigantea was collected from an unidentified fallen angiosperms twig from Bilaspur, Himachal Pradesh (India). The fungus was isolated on malt extract agar which is prepare according to given instructions and then isolated in a sterile condition by single hyphal tip in Petri-plates kept at $24^{\circ} \mathrm{C}$. The mycelium was sub cultured on the same medium for further experimentation.

\section{Procedure}

P. gigantea shows a different effect in basal media, temperature, $\mathrm{pH}$, days of incubation, and carbon and nitrogen source in static conditions. The fungus culture was grown in $100 \mathrm{ml}$ Erlenmeyer flasks containing $25 \mathrm{ml}$ of 
the basal medium which was autoclaved at 15 psi pressure for 15-20 min. Each flask was inoculated aseptically under sterile condition with an agar plug of $10 \mathrm{~mm}$ diameter cut from the periphery of a culture with a mycelial inoculum. Replicates of each medium are kept for further analysis.

Determination of mycelial dry weight was done through Whatman filter paper No. 1 and dried at $45^{\circ} \mathrm{C}$ in a hot air oven, and the dry weight was measured using an electronic balance (Sartorius Analytical BL 210S). The final pH of the culture filtrate of the individual replicate was checked over digital pH Meter 813.

\section{Basal Media}

Different selected basal media with different components, viz., Raulin's, Richard's, Dox's, Coon's, Brown's I, Brown's II, glucose-peptone, glucose-nitrate, Czapek's I, Czapek's II, Asthana and Hawker's and Elliot's medium are used for growth.(Prasher and Chauhan., 2015).

\section{Temperature}

The fungus was incubated at selected temperatures 16, 20, 24,28 , and $32^{\circ} \mathrm{C}$ to assess the growth of glucose-peptone medium with a $\mathrm{pH}$ of 5 for 10 days of incubation (selected arbitrarily).

\section{$\mathrm{H}^{+}$ion Concentration}

The $\mathrm{H}^{+}$ion concentration of the medium was adjusted to (3.0-9.0) with sterile $1 \mathrm{~N}-\mathrm{HCL}$ and $1 \mathrm{~N}-\mathrm{KOH}$ and checked with digital $\mathrm{pH}$ Meter 813 . The flasks were incubated for 10 days at $28^{\circ} \mathrm{C}$.

\section{Incubation Phase}

Days of incubation with respect to effect on growth and reproduction of the fungus was studied for 30 days, at an optimum temperature of $28^{\circ} \mathrm{C}$ and optimum $\mathrm{pH}$ of 5.0.

\section{Carbon Sources}

The best carbon sources were studied out of which the glucose-peptone medium was supplemented by carbon sources individually by replacing the glucose with an equivalent amount of carbon. The medium devoid of glucose serves as a control for carbon.

\section{Inorganic and Organic Nitrogen Source}

The nitrogen sources were evaluated by replacing the peptone with amino acids and inorganic nitrogen compounds $(0.15 \mathrm{~g} / \mathrm{l})$ at optimum conditions, i.e., at $28^{\circ} \mathrm{C}$ and $\mathrm{pH} 5.0$ in glucose supplemented basal medium for 12 days of incubation and nitrogen served as control.

\section{Statistical analysis}

The results obtained were tested in a one-way ANOVA and evaluated by SPSS software in which Tukey's test was used. Data were analyzed the mean triplicates \pm standard deviation.

\section{RESULTS}

\section{Effect of Basal Media}

Glucose-peptone medium supported the optimum growth of the fungus (Figure 1). The fungus produced narrow thin walled, profusely branched, clamped hyphae in all the treatments. Elliot's medium supported the least growth of the fungus.

\section{Effect of Temperature and $\mathrm{pH}$}

The maximum dry weight was produced at $28^{\circ} \mathrm{C}$ whereas the fungus showed the least growth at $20^{\circ} \mathrm{C}$ (Figure 2a). The most favorable $\mathrm{pH}$ concentration for the mycelial growth of the fungus is 5.0. It did not show any growth at $\mathrm{pH} 3.0$ (Figure 2b).

\section{Effect of Days of Incubation}

The fungus attained maximum growth on the $12^{\text {th }}$ day of incubation afterward it decreased (Figure 3).

\section{Effect of Carbon Source}

The preeminent carbon source for the growth of the fungus was found to be $\mathrm{D}(+)$ Glucose whereas the fungus did not show any growth with sucrose (Figure 4). The optimum production of biomass (average mycelial dry weight) in relation to the amount of sugar consumed (economic coefficient) in decreasing order is $\mathrm{D}(+)$ glucose $>$ maltose $>$ pectin $>\mathrm{D}(+)$ lactose $>$ starch $>\mathrm{L}(-)$ sorbose $>\mathrm{D}(+)$ raffinose $>\mathrm{D}(+)$ xylose $>$ fructose $>$ sucrose. The fungus exhibited only vegetative growth.

\section{Effect of Inorganic Nitrogen Sources}

The best inorganic nitrogen source for the growth of the fungus is sodium nitrate. The least mycelial growth of the

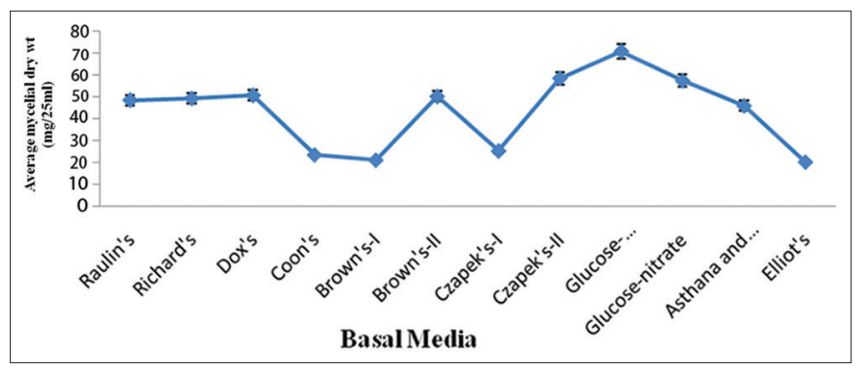

Figure 1: Average mycelial dry wt of Phlebiopsis gigantea with different basal media 


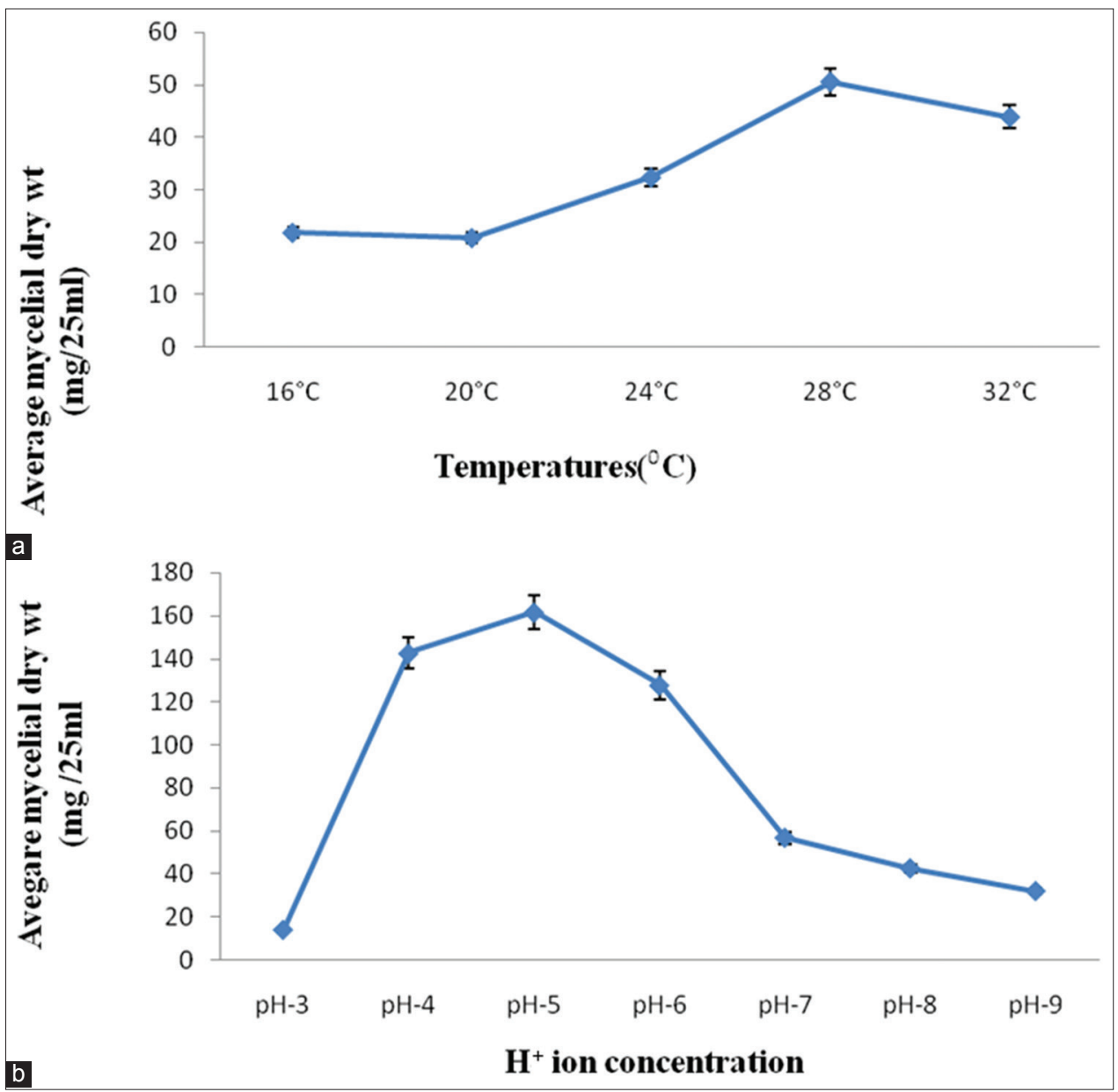

Figure 2: (a) Average mycelial dry wt.-mg/25 $\mathrm{ml}$ of Phlebiopsis gigantea with different $\mathrm{H}^{+}$ion concentrations, (b) average mycelial dry wt of Phlebiopsis gigantea with different temperatures

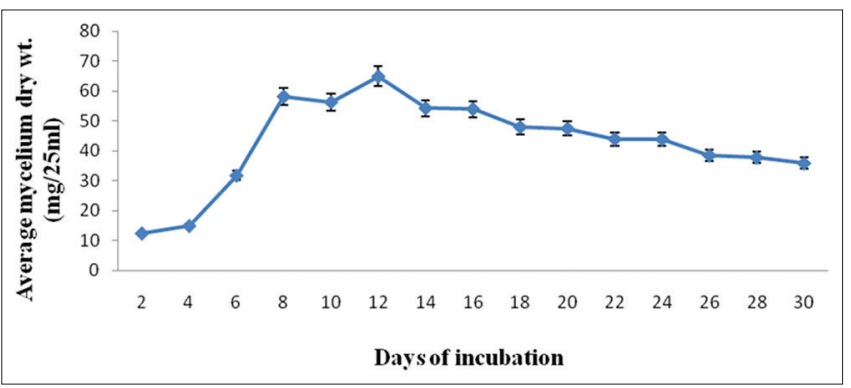

Figure 3: Average mycelial dry wt.-mg/25 $\mathrm{ml}$ of Phlebiopsis gigantea with different days

fungus was observed with ammonium nitrate (Figure 5a). The optimum production of biomass (average mycelia dry weight) in relation to the amount of sugar consumed (economic coefficient) in decreasing order was sodium nitrate $>$ potassium nitrate $>$ ammonium phosphate $>$ ammonium sulfate $>$ sodium nitrite $>$ ammonium chloride $>$ ammonium oxalate $>$ ammonium acetate $>$ ammonium nitrate. The fungus produced chlamydospores in ammonium acetate whereas it remained in a vegetative state in other treatments.

\section{Effect of Organic Nitrogen Sources}

The best organic nitrogen compound for the mycelial growth of fungus was L-ornithine monohydrochloride (Figure 5b). The optimum production of biomass (average mycelial dry weight) in relation to the amount of sugar consumed (economic coefficient) in decreasing order was DL-threonine $>$ L-arginine $\mathrm{HCL}>$ L-ornithine mono HCL $>$ L-Lysine mono HCL $>$ L-proline $>$ L-isoleucine $>$ L-Tyrosine $>$ Glycine $>$ L-cystine $>$ DL-serine $>$ L-cysteine mono HCL $>$ L-norleucine $>$ L-histidine HCL $>$ Dihydroxyphenylalanine $>$ L-glutamic acid $>$ DL-aspartic acid $>$ DL-valine $>$ DLalanine $>$ DL-tryptophan $>$ DL-2-amino-n-butyricacid $>$ DL-methionine. The fungus produced chlamydospores in valine and L-lysine monohydrochloride whereas, in all other organic nitrogen compounds formed profusely branched, septate hyphae were produced.

\section{DISCUSSION}

The studies reveal interesting results regarding growth and reproduction behaviour of the fungus. The best 
medium for the optimum growth of the fungus is Glucose-peptone medium. The optimum temperature $\left(28^{\circ} \mathrm{C}\right)$ and $\mathrm{pH}(5.0)$ is required for the optimum mycelial production of $P$. gigantea after 12 days of incubation. High temperature $\left(32^{\circ} \mathrm{C}\right)$ and highly acidic $\mathrm{pH}(\mathrm{pH}-3)$ are found to be inhibitory for its growth. It has been found that composition of the basal medium, temperature and $\mathrm{pH}$ has a significant effect on the growth of fungus.

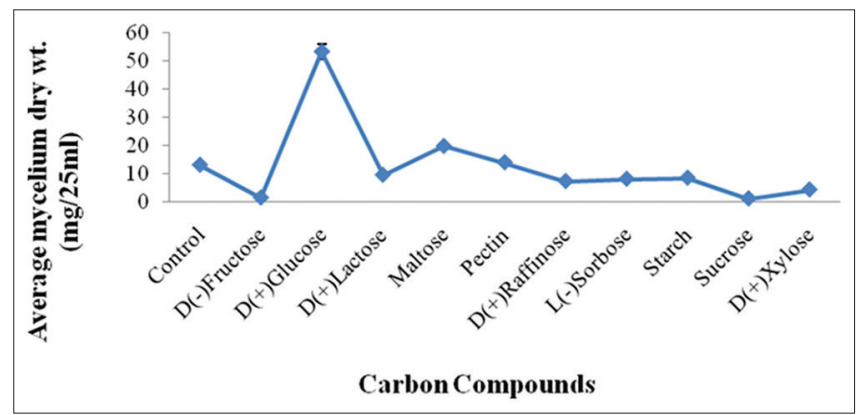

Figure 4: Average mycelial dry wt.-mg/25 $\mathrm{ml}$ of Phlebiopsis gigantea with different carbon compounds
The fungus shows maximum biomass production with $\mathrm{D}(+)$ Glucose shows stimulating effect according to the previous report on carbon and nitrogen compounds on mycelial growth in Pleurotus eryngii (Mirjana et al., 2006), Pleurotus ostreatus (Nwokoye et al., 2010) and maltose, pectin, $\mathrm{D}(+)$ lactose, starch, $\mathrm{L}(-)$ sorbose, $\mathrm{D}(+)$ raffinose, $\mathrm{D}(+)$ xylose, fructose, and sucrose supported moderate growth of the fungus.

Studies on inorganic nitrogenous compounds reveal that the fungus gives maximum growth with sodium nitrate and produce chlamydospores in ammonium acetate followed by potassium nitrate, ammonium phosphate, ammonium sulfate, sodium nitrite, ammonium chloride, ammonium oxalate, ammonium acetate, and ammonium nitrate. However, some wood rot fungi utilize nitrate nitrogen slowly in stationary culture (Natia et al., 2012). The sodium nitrate supported better growth in Lenzites steroids, and the ammonium nitrate as sole nitrogen source produced better growth in Hexagonia apiaria (Praveen and Arun, 2013). Inorganic nitrogen source, out of

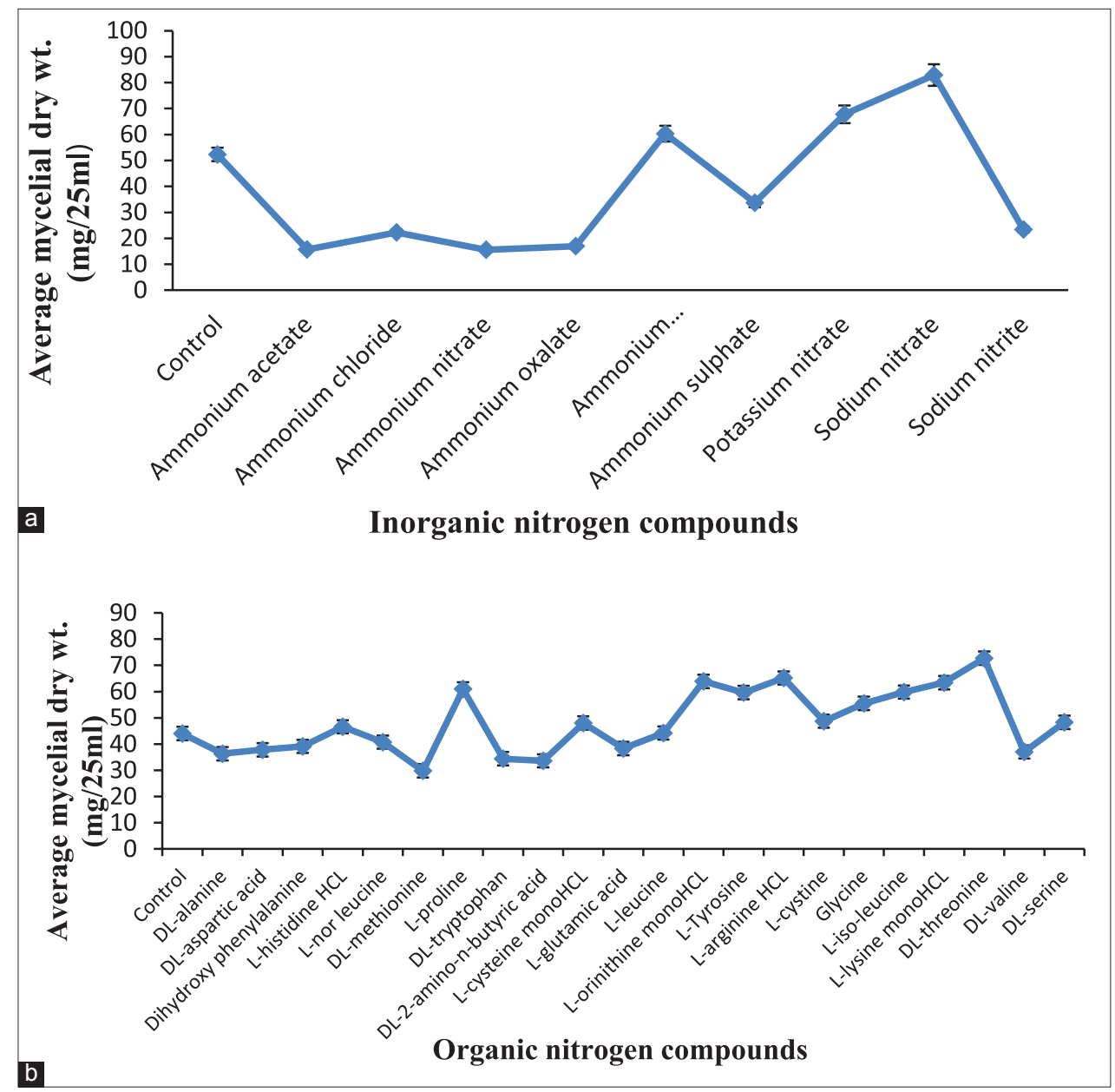

Figure 5: (a) Average mycelia dry wt.-mg/25 $\mathrm{ml}$ of Phlebiopsis gigantea with different inorganic nitrogenous compounds, (b) Average mycelia dry wt.-mg/25 $\mathrm{ml}$ of Phlebiopsis gigantea with different organic nitrogenous compounds 
22 amino acids, DL-threonine showed good mycelia growth. L-proline, L-ornithine mono HCL, L-arginine HCL showed moderate growth. However, these results contrary to other findings where it supports good growth of isoleucine in Penicillium citrinum (Kozlovskii et al., 2006) and good growth in proline (Garg and Mehrotra, 1976).

\section{CONCLUSION}

The data can be utilized to increases the production and to understand the effect of physical factors on mycelia growth which is useful for prerequisite experimentation and also useful in industrial purpose.

\section{ACKNOWLEDGMENTS}

The author would like to thank the Chairpersons of Department of Botany and Department Environment Studies, Panjab University, for providing the necessary facilities. Prasher is thankful to U.G.C, (SAP, DRS-III) in the Department of Botany for infrastructural support. Rajeev Kumar is thankful to DST (SERB)-SB/EMEQ$042 / 2014$ for providing financial assistance for the work. Sushma Negi acknowledges the UGC for financial assistance to UGC grant (NFHE) during the course of study.

\section{REFERENCES}

Asiegbu FO, Daniel G, Johansson M. Cellular interaction between the saprotrops Phlebiopsis gigantea and nonsuberised roots of Picea abies. Mycol Res 1996;100:409-17.

Garg DK, Mehrotra RS. The effect of certain carbohydrates and amino acids on growth and respiration of Fusarium solarli f.sp. pisi. Phytopathol Mediterr 1976;15:103-5.

Hacskaylo J, Lilly LG, Barnett HL. Growth of fungi on three sources of nitrogen. Mycologia 1954;46:691-701.

Kozlovskii AG, Zhelifonova VP, Antipova TV, Lysanskaya VY. The effect of some ammino acids on the growth and biosynthesis of ergot alkaloids and quinocitrinins in the fungus Penicillium citrinum Thom 1910. Microbiology 2006; 75:334-41.
Mirjana S, Limor P, Dana F, Yitzhak H, Solomon PW, Eviatar N, et al. Effect on different carbon and nitrogen sources on laccase and peroxidases production by selected Pleurotus species. Enzyme Microb Technol 2006;38:65-73.

Natia K, Vladimir E, Wasser PS. Effect of carbon, nitrogen sources, and copper concentration on the ligninolytic enzyme production by Coriolopsis gallica. J Waste Convers Bioprod Biotechnol 2012;1:22-7.

Nwokoye AI, Kuforiji OO, Oni PI. Studies on mycelial growth requirements of Pleurotus ostreatus (Fr.) singer. Int J Basic Appl Sci 2010;10:47-9.

Prasher I, Chauhan R. Effect of carbon and nitrogen sources on the growth, reproduction and ligninolytic enzymes activity of Dictyoarthrinium synnematicum somrith. Adv Zool Bot 2015;3:24-30.

Prasher IB. Wood rotting non-gilled Agaricomycetes of himalayas, fungal diversity research series. 2015:403-5. DOI: 10.1007/978-94-017-9858-7.

Pratt JE, Gibbs JN, Webber JF. Registration of Phlebiopsis giganatea as a forest biocontrol agent in the U.K: Recent experience. Biocontrol Sci Technol 1999;9:113-8.

Pratt JE, Niemi M, Sierota ZH. Comparison of three products based on Phlebiopsis gigantea for the control of Heterobasidion annosum in Europe. Biocontrol SciTechnol 2000;10:467-77.

Praveen NK, Arun A. Effect of carbon and nitrogen on the growth of lignicolous fungi from Rathanmahal wildlife sanctuary, Gujarat India. Int J Sci Nat 2013;4:237-45.

Sun H, Korhonen K, Hantula J, Asiegbu FO, Kasanen R. Use of a breeding approach for improving biocontrol efficacy of Phlebiopsis gigantea strains against Heterobasidion infection of Norway spruce stumps. FEMS Microbiol Ecol 2009;69:266-73.

Vasiliauskas R, Menkis A, Finlay RD, Stenlid J. Wood-decay fungi in fine living roots of conifer seedlings. New Phytol 2007;174:441-6.

Wadekar RV, North MJ, Watkinson SC. Proteolytic activities in two wood-decaying basidiomycete fungi, Serpula lacrymans and Coriolus versicolor. Microbiology 1995;141:1575-83.

Woodward S, Stenld J, Karjalainen R, Huttermann A. Heterobasidion annosum Biology, Ecology, Impact and Control.Wallingford, UK: CAB International; 1998. p. 589. 